\title{
La impostura educativa y democrática en Colombia bajo el régimen de la Constitución de 1991*
}

\author{
Juan Gabriel Gómez Albarello \\ Universidad Nacional de Colombia, Bogotá, Colombia \\ jggomeza@unal.edu.co \\ https://orcid.org/0000-0001-9097-763X
}

\section{RESUMEN}

El mandato de los artículos 41, 45, 67 bosquejo una propuesta orientada a hacer y 68 de la Constitución colombiana (1991) puede ser resumido en un solo principio: la educación debe ser democrática. Este principio está lejos de realizarse. En este artículo presento evidencia de su falta de realización y un análisis de sus posibles democráticoelsistemaeducativodemodoque contribuya a hacer realmente democrática la precaria "democracia" colombiana.

Palabras clave: educación democrática; lazos secundordiales; currículo oculto; ejemplo.

causas. A modo de conclusión, formulo el

Cómo citar: Gómez Albarello, J. (2021). La impostura educativa y democrática en Colombia bajo el régimen de la Constitución de 1991. Ciencias Sociales y Educación, 10(20), 85-111. https://doi.org/10.22395/csye.v10n20a5 Recibido: 11 de mayo de 2021.

Aprobado: 15 de junio de 2021. 


\section{Educational and Democratic Imposture in Colombia under the 1991 Constitution Regime}

ABSTRACT

The mandate of articles 41, 45, 67 and 68 of the 1991 Constitution of Colombia can be summarized in a single principle: education must be democratic. This principle is far from being realized. In this article, I present evidence of its lack of realization, and an analysis of its possible causes. By way of conclusion, I outline a proposal aimed at making our educational system democratic so that it might contribute to making the precarious Colombian 'democracy' truly democratic.

Keywords: democratic education; secondordial ties; hidden curriculum, example.

\section{A impostura educativa e democrática na Colômbia sob o regime da Constituição de 1991}

RESUMO

O mandato dos artigos 41, 45, 67 e 68 da Constituição colombiana de 1991 pode ser resumido num único princípio: a educação deve ser democrática. Este princípio está longe de ser realizado. Neste artigo, apresento evidência de sua falta de realização e uma análise de suas possíveis causas. A título de conclusão, formulo as linhas gerais de uma proposta que visa democratizar o sistema educacional de forma a contribuir para a democratização da precária 'democracia' colombiana.

Palavras-chave: educação democrática; vínculos secundordiales; currículo oculto; exemplo. 


\section{Introducción}

A diferencia de muchas de las constituciones que fueron promulgadas en el Siglo XIX y de buena parte de las reformas a la Constitución (1886) realizadas en el Siglo XX en Colombia (Valencia Villa, 1987), la Constitución (1991) fue el resultado de un amplio acuerdo suscrito por fuerzas políticas bastante diversas (Dugas, 1993). Las numerosísimas disposiciones de la Constitución fueron aprobadas por amplias mayorías (Cepeda, 1993). Sin embargo, ese acuerdo no logró transformar la política colombiana. Las instituciones creadas por ese pacto constitucional no tuvieron el efecto que sus autores se propusieron alcanzar. Muchos de los análisis realizados a este respecto tienen que ver con las instituciones de representación política, como por ejemplo Gómez Albarello (2019). Aunque esas instituciones no son ni la cabeza ni el centro de la sociedad ${ }^{1}$, su función es claramente la de decidir sobre políticas públicas de alcance general $\mathrm{y}$, de ese modo, contribuir a mantener la unidad de la sociedad.

En este artículo quisiera concentrarme en una dimensión usualmente soslayada en los análisis acerca del impacto de la Constitución (1991) en la política colombiana: el fracaso para realizar los principios constitucionales que establecen que todas las personas en Colombia han de ser educadas en el respeto a los derechos humanos, a la paz y a la democracia (art. 67), que la comunidad educativa participará en la dirección de las instituciones de educación (art. 68) y que esa educación ha de ser realizada mediante el estudio de la Constitución y mediante prácticas democráticas (art. 41); en pocas palabras, que la educación para la democracia sea democrática ${ }^{2}$. En la primera parte del artículo procuro mostrar porqué la educación para la democracia debe ser democrática, luego de lo cual hago referencia al modelo de democracia que concuerda con este principio constitucional. La segunda parte está dedicada a mostrar el fracaso en la realización de este principio, así como sus causas. A modo de conclusión, formularé el bosquejo de una propuesta orientada a hacer democrático el sistema

En el Siglo XII, John de Salisbury (1990) acuñó la idea de que la unidad política era un "cuerpo político" y que su cabeza era el príncipe. En la edad moderna, las revoluciones liberales conservaron la metáfora del cuerpo político, pero pusieron las asambleas elegidas popularmente en el lugar del príncipe. Con el abandono de esta metáfora y su sustitución por otra de carácter espacial, los órganos representativos han sido concebidos como el "centro" de la unidad política. Sin embargo, esta concepción ha sido descartada por cuenta de la diferenciación funcional de la sociedad en esferas autónomas (Habermas, 1989; Luhmann,1993).

2 La importancia de este principio puede ser resaltada tomando nota del hecho de que los constituyentes de 1991 lo reiteraron varias veces. Uno puede juzgar esta reiteración como un defecto manifiesto de técnica normativa pues la redundancia desdice de la calidad formal de un texto constitucional. Sin embargo, esa misma redundancia disipa cualquier duda que pudiese haber acerca del hecho de que el modelo de democracia de la Constitución (1991) demanda una educación democrática. Además de los artículos ya citados, el artículo 45 establece que "el Estado y la sociedad garantizan la participación activa de los jóvenes en los organismos públicos y privados que tengan a cargo la protección, educación y progreso de la juventud". 
educativo de modo que contribuya a hacer realmente democrática la precaria "democracia" colombiana.

\section{Una educación democrática para la democracia}

La Constitución de Colombia (1991) no es la primera en afirmar que la educación debe ser democrática, esto es, que no basta enseñar valores democráticos, sino que también es necesario impartir esa enseñanza mediante prácticas democráticas. Las constituciones de México (1917), reformada en 1946 (artículo 3, II a); Panamá (art. 91, en la actualidad art. 87, 1972) y Nicaragua (art. 117, 1987) también contienen el mandato de que la educación debe ser democrática. Constituciones promulgadas posteriormente como la de Venezuela (art. 102, 1999) y Bolivia (art. 177, III, 2009) han incluido un mandato similar. Esto las hace más radicales que aquellas que se limitan a establecer el deber de que la educación debe impartir valores democráticos, como lo establecen las constituciones de Honduras (art. 151, 1982), El Salvador (art. 55, 1983), Paraguay (art. 73, 1992) y Ecuador (art. 66, 2008).

El mandato constitucional que establece que la educación debe ser democrática demanda una reflexión acerca de su significado. En una clave liberal, uno podría postular que en una sociedad plural las constituciones deberían guardar silencio acerca de la forma en la cual la ciudadanía debe ser educada. La toma de partido por la educación laica, como lo hacen por ejemplo las constituciones de Honduras y México, iría en contra del derecho de padres y madres a educar a su progenie de acuerdo con valores religiosos. En efecto, si un régimen liberal reconoce la libertad de consciencia y la libertad religiosa, de ese reconocimiento se seguiría que quienes quisieran educar a su prole con valores religiosos pudiesen fundar y asociarse a escuelas con una orientación abiertamente religiosa.

La objeción liberal puede ser incluso de mucho mayor alcance. Si se parte de la idea de que los principios constitucionales tienen un valor procedimental pues su finalidad es asegurar la convivencia de grupos que tienen diferentes definiciones de vida buena (Rawls, 1971), entonces las constituciones no deberían inmiscuirse en la regulación de la forma como debe llevarse a cabo la educación. Si lo hicieran, estarían cruzando la frontera que separa el acuerdo acerca de lo justo, por un parte, de las definiciones culturales de vida buena a las cuales se adhieren los individuos por mor de su pertenencia a una determinada comunidad y a una cierta tradición, por la otra. De acuerdo con esta formulación de la teoría liberal, la idea de la justicia en una sociedad bien ordenada no debería sobrecargar a los individuos con la exigencia de adquirir virtudes democráticas por medio de la educación. La virtud y el vicio serían definiciones éticas, no morales, esto es, valoraciones idiosincráticas de la 
acción humana, dependientes de la tradición y la experiencia de cada comunidad, no juicios imparciales cuya validez sería universal. Lo que pediría la teoría liberal a la ciudadanía sería meramente la adhesión a los principios y las reglas procedimentales de acuerdo con los cuales los grupos que profesan creencias diversas pueden llegar a acuerdos relativos a la regulación de su vida en común (Holmes, 1995, p. 175).

El agnosticismo liberal acerca de la educación de la ciudadanía es cuestionable. John Dewey (1916) delineó un contraste entre sociedades basadas en la tradición y sociedades basadas en la innovación del cual derivó un fuerte argumento en favor del carácter democrático de la educación. En efecto, según Dewey, en una sociedad basada en la continuidad de la tradición, lo que los educandos tienen que aprender es a enmarcar los problemas que se les presentarán en el futuro dentro de esa tradición para extraer de ella las correspondientes soluciones. Por el contrario, en una sociedad basada en la innovación y en el progreso, la ciudadanía se enfrentará continuamente a problemas nuevos para los cuales ninguna tradición tendrá soluciones claramente definidas. De ahí que los educandos tengan que adquirir el hábito de la indagación y la reflexión acerca de los valores en juego, los medios adecuados para la solución de los problemas y la consideración de las consecuencias de una u otra solución. Puesto que, en una sociedad democrática la solución será escogida en el marco de un proceso de deliberación colectiva, de ello se sigue que los educandos han de adquirir el hábito no sólo de investigar libremente sino de tomar en consideración la perspectiva de todos los participantes en el proceso de decisión.

Una sociedad autoritaria, no expuesta a cambios, puede darse el lujo de educar su niñez y juventud en el hábito de repetir lo que han aprendido sus mayores. Por el contrario, una sociedad democrática, en la cual la libre iniciativa genera continuamente oportunidades de cambio, estará expuesta a la disrupción y el desorden, a menos que sus miembros tengan la capacidad para definir la novedad de los problemas que tienen que resolver y la libertad para buscar diversas soluciones, así como las destrezas sociales para tomar en cuenta las perspectivas de sus conciudadanos y para articular una perspectiva común. Los educandos de una escuela autoritaria muy difícilmente estarán a la altura de estos desafíos pues sus hábitos mentales no concuerdan con lo que se espera de ellos en una sociedad democrática.

Una sociedad en la cual la gente tiene que estudiar simplemente para ganarse la vida realizando tareas que no considera significativas ni ennoblecedoras puede conformarse con que sus miembros se limiten a aprender a leer, escribir, sumar, restar, multiplicar y dividir, así como a adquirir competencias adicionales, según su tipo de trabajo (Dewey, 1916, p. 226). Si en esa 
sociedad los encargados de tomar las decisiones son elegidos popularmente y si, ocasionalmente, la ciudadanía es llamada a participar en procesos colectivos de decisión, entonces las mismas competencias básicas referidas anteriormente podrían considerarse suficientes. Por el contrario, una sociedad que le atribuye valor a la participación de sus miembros en las decisiones que los afectan y que los llama a jugar un papel activo en la vida de la nación no puede contentarse con una educación semejante.

La educación que requiere una nación que se define a sí misma como "democrática, participativa y pluralista" ha de ser democrática. Tiene que ser una educación que haga a sus discentes sujetos, no meros objetos del proceso educativo, de lo cual se sigue que esos discentes han de tener la libertad para indagar y experimentar sin las restricciones escolásticas de un currículo único usualmente descontextualizado, así como para deliberar y decidir con otros acerca del significado y alcance de sus indagaciones y experimentos. Esta libertad no contradice el postulado de que la ciudadanía deba adquirir una serie de virtudes comunes durante su proceso educativo formal. Antes bien, esa libertad es un componente esencial de esas virtudes. Conviene recalcar que quienes se forman en el hábito de la libre indagación han de ser educados, además, en el reconocimiento de la libertad de sus compañeros y, por tanto, en la capacidad para que las soluciones colectivas articulen los puntos de vista de todos los involucrados (Honneth, 2013, p. 389).

Llegados a este punto, es posible indicar a qué modelo de democracia corresponde el principio constitucional de que la educación debe ser democrática. La Constitución (1991) claramente optó por un modelo en el cual, además de escoger representantes, la ciudadanía ha de contar con múltiples oportunidades para incidir en las decisiones que le conciernen tanto a nivel nacional, como regional y local, y tanto a nivel público como a nivel privado ${ }^{3}$. Este modelo de democracia representativa y participativa demanda a la ciudadanía el desempeño de un rol activo en la vida de la nación. Esa es la razón por la cual la Constitución (1991) establece que uno de los deberes ciudadanos es precisamente el de "participar en la vida política, cívica y comunitaria del país" (art. 95, núm. 5). Una constitución de este tipo no puede ser indiferente con respecto al carácter de la ciudadanía

De manera expresa, la Constitución (1991) establece que el servicio de salud se debe organizar con participación de la comunidad (art. 49), que la provisión de los servicios públicos por parte de empresas estatales debe contar con la participación de los usuarios (art. 369), que las organizaciones de usuarios y consumidores participarán en el estudio de las disposiciones que les conciernen (art. 78) y que la comunidad debe participar en las decisiones que afecten el medio ambiente (art. 79). No menos importante es el mandato constitucional de que las asociaciones de la sociedad civil ("asociaciones profesionales, cívicas, sindicales, comunitarias, juveniles, benéficas o de utilidad común no gubernamentales") deben tener una estructura democrática proveyendo "instancias de participación, concertación, control y vigilancia" de su gestión pública (art. 103). La Constitución (1991) estableció, además, la posibilidad de que el legislador pueda establecer "los estímulos y medios para que los trabajadores participen en la gestión de las empresas" (art. 57). 
a la cual le confía el funcionamiento de muchas de sus instituciones. Por eso, los autores del texto constitucional establecieron que la formación ciudadana tiene que ser democrática.

El modelo convencional de democracia, indirecta y representativa concibe el proceso político como un mercado en el cual en el lado de la oferta están los partidos y en el lado de la demanda la ciudadanía. De acuerdo con este modelo, la política es como el mercado en el sentido de que es un proceso regulado de competencia de organizaciones que ofrecen a los electores políticas públicas, del mismo modo que las empresas ofrecen bienes y servicios a los consumidores. En este proceso competitivo e instrumental se agota la mayor parte de su significado. En línea con este modelo, la ciudadanía es meramente una consumidora de mensajes relativos a las políticas públicas que más la beneficiarían. Así pues, del lado de la ciudadanía, el proceso político concierne fundamentalmente al registro de las preferencias de los votantes y en su traducción en propuestas de gobierno.

Un régimen constitucional que postula que la ciudadanía debe participar activamente en la vida de la nación y que, por ello, debe formarse democráticamente, encarna un modelo de democracia enteramente distinto. En este modelo la ciudadanía es una comunidad que se educa continuamente, esto es, que desarrolla sus capacidades de un modo que enaltece y ennoblece su vida. Por tanto, su relación con el proceso político no es instrumental; no se agota en la selección de los medios más efectivos para la realización de fines privados. Antes bien, su relación con el proceso político es la de agentes que despliegan su capacidad de aprendizaje para comprender juntos sus problemas comunes y encontrar juntos soluciones de beneficio común, y de este modo se reconocen recíprocamente como sujetos que aspiran a una vida justa y buena ${ }^{4}$.

\section{El fracaso democrático en el sistema educativo colombiano: su evidencia y sus posibles causas}

La intención de los autores del texto constitucional colombiano (1991) está lejos de ser realizada. En este artículo quisiera proporcionar evidencia del fracaso de la sociedad colombiana para realizar el postulado constitucional de que la educación para la democracia sea democrática y, además, considerar las posibles causas de ese fracaso. Los factores que tomaré en consideración son los siguientes: la escasa e inadecuada pedagogía constitucional; el vaciamiento electoral de la democracia en la escuela y la universidad; las prácticas clientelistas y gremialistas, así como la prevalencia de 'roscas' en los establecimientos educativos; la limitadísima capacidad de maestros y estudiantes para poner

Aquí he seguido la línea de análisis de C. B. Macpherson (1977), así como la de Samuel Bowles y Herbert Gintis (1987) acerca del contraste entre modelos de democracia que conciben la política en términos instrumentales y aquellos que la asocian al desarrollo de las personas. 
en cuestión los malos ejemplos de la vida política; y, finalmente, la vigencia de un currículo oculto de adaptación a un sistema político, económico y social que está en contradicción con los valores y principios constitucionales.

\section{La evidencia}

Uno de los más graves signos del deterioro de la cultura política colombiana es el aumento de personas que dicen estar dispuestas a apoyar a un líder que prescinda del Congreso. Es cierto que este es un fenómeno que ha tenido lugar en muchos otros países. De acuerdo con las cifras de la Encuesta Mundial de Valores, el porcentaje de personas que en los Estados Unidos apoyaría a un líder de este tipo pasó de 32 \% en el 2006 a 34 \% en el 2011 y luego a 38 \% en el 2017. En Colombia, este es un fenómeno mucho más alarmante. El referido porcentaje pasó de $30 \%$ en el 2005 a $52 \%$ en el 2012 y luego a 60 \% en el 2018. Este aumento es, parcialmente, una consecuencia de la muy limitada confianza que la ciudadanía tiene hoy en los partidos políticos, así como en el Congreso. Sin embargo, conviene tener en cuenta lo siguiente. Si bien esa confianza se ha reducido sustancialmente, no en todos los países la ciudadanía está dispuesta a apoyar ampliamente a líderes autoritarios. La tentación populista es más pronunciada en países que tienen una cultura política más autoritaria que democrática. Tal parece ser el caso de Colombia ${ }^{5}$.

En el año 2016, el profesor de la Universidad de Massachusetts, en Amherst, Matthew MacWilliams (2016) reportó que el rasgo decisivo para saber si una persona apoyaría al líder populista Donald Trump sería que tuviera una personalidad autoritaria. Para llegar a esa conclusión, realizó una encuesta en la cual utilizó la escala desarrollada por el estudioso Stanley Feldman. Esta es una medición que circunvala la actitud defensiva con la cual las personas autoritarias se niegan a reconocerse como tales pues recurre a una estrategia indirecta consistente en cuatro preguntas acerca del tipo de educación que la persona encuestada estima adecuada para sus hijos. En el 2017, una firma encuestadora, el Centro Nacional de Consultoría, utilizó la misma metodología y encontró que el 61 \% de los colombianos tiene un carácter autoritario (Semana, 2017).

En la más reciente ola de la Encuesta Mundial de Valores (2017-2020), el promedio de los más de 70 países encuestados indica que sólo el $25 \%$ de la ciudadanía confía en los partidos políticos y sólo el 35 \% en el parlamento. Sin embargo, la desconfianza ciudadana no se traduce automáticamente en el apoyo a líderes dispuestos a desconocer a los órganos representativos. En efecto, el coeficiente de la correlación entre la confianza en los partidos y el apoyo a líderes autoritarios es -0,28 ( $p<000,1)$. Este coeficiente es estadísticamente significativo y tiene el signo correcto, esto es, a mayor confianza en los partidos menor es la confianza en líderes autoritarios. Sin embargo, la dispersión de los datos es muy amplia. Otro tanto sucede con el coeficiente de la correlación entre la confianza en el parlamento y el apoyo a líderes autoritarios el cual es -0,04, $(p<000,1)$. Esto refuerza lo dicho arriba: la menor confianza en los partidos y en el parlamento sólo se traduce en un amplio apoyo a líderes populistas allí donde hay una cultura política autoritaria. 
Uno podría replicar que ese dato no refleja el efecto que ha tenido la Constitución de 1991 en la cultura política colombiana pues engloba a personas de varias generaciones, muchas de las cuales se educaron bajo el régimen de la autoritaria Constitución (1886). No obstante, otras mediciones muestran que la juventud de hoy crece imbuida de valores autoritarios, no democráticos. En efecto, los estudios de la Asociación Internacional para la Evaluación de los Logros Educativos (IEA, por su acrónimo en inglés) proporcionan una evidencia muy preocupante de esta realidad. Tres cuartas partes de los jóvenes colombianos encuestados en el 2009 y en el 2016 considera que una dictadura se justifica, cuando genera orden y seguridad. En ambos estudios, un poco más de dos terceras partes considera que también una dictadura se justifica, cuando genera beneficios económicos. Estos mismos estudios muestran una también preocupante aprobación de prácticas autoritarias (48 \%) y corruptas $(49 \%)^{6}$. No obstante, hay una dimensión en la cual ha habido un significativo progreso: en la desaprobación de la violencia. A diferencia de sus pares latinoamericanos, los jóvenes colombianos están mucho menos inclinados a aprobar la justicia por mano propia (41 \%) o el uso de la violencia contra quienes han cometido crímenes contra su familia (26 \%). Además, se muestran mayoritariamente favorables a la idea de que la paz ha de alcanzarse mediante el diálogo y la negociación (80 \%) (Schulz et al., 2018).

Coloquialmente, muchas de las personas que expresan pesimismo acerca de la capacidad del sistema político para reformarse ponen, sin embargo, su esperanza en la educación. Consideran que la superación de la dinámica facciosa y las prácticas clientelistas y corruptas podrá realizarse en el largo plazo mediante la inversión de grandes esfuerzos en el sistema educativo. A la luz de la evidencia que presenté anteriormente, esa esperanza es infundada. Tal parece que las nuevas generaciones seguirán reproduciendo los mismos vicios que aquejan la vida pública y privada colombiana, a menos que haya una reforma educativa que haga por fin democrática la formación de la niñez y la juventud. El primer paso para realizar una reforma de ese tipo es realizar un diagnóstico de las causas del déficit democrático del sistema educativo colombiano.

En las encuestas realizadas por el IEA (2009 y 2016), se les pregunta a los estudiantes si aprueban afirmaciones como las siguientes: "es mejor que los líderes gubernamentales tomen sus decisiones sin consultar a nadie; la gente que tiene opiniones diferentes del gobierno deben ser considerados enemigos; es correcto que el gobierno no cumpla con la ley, cuando lo considera necesario; la concentración de poder en una persona garantiza el orden; el gobierno debe cerrar los medios de comunicación que son críticos; si el Presidente no está de acuerdo con el Congreso, debe disolverlo; es aceptable que un empleado público acepte sobornos, si su salario es demasiado bajo; es aceptable que un empleado público utilice los recursos de la institución en la cual trabaja para su propio beneficio; los buenos candidatos deben darle beneficios personales a los votantes a cambio de sus votos; es aceptable que un empleado público ayude a sus amigos a obtener trabajo en su despacho". Estudios de caso, como el de Medina et al. (2016), confirman la prevalencia de estas actitudes. 


\section{El escaso conocimiento del texto constitucional y la pedagogía pedante de los máximos tribunales}

Hasta cierto punto es comprensible que los primeros años de vigencia de la Constitución se hayan caracterizado por una grave deficiencia en materia de pedagogía constitucional. Uno puede concederle el beneficio de la duda a las instituciones públicas encargadas de promover la enseñanza de la Constitución, las cuales tempranamente se esforzaron por fomentar la adquisición de conocimientos cívicos y disposiciones democráticas en los establecimientos educativos. Con tal fin, en 1994, el Congreso de Colombia aprobó las leyes 107 y 115. Empero, el resultado de este esfuerzo no fue positivo. Durante los años 1994 y 2000 , cuando los estudiantes colombianos compararon por primera vez sus conocimientos cívicos con los de otros 27 países, ocuparon el último lugar. Sus respuestas dejaron en evidencia no sólo su precario entendimiento de nociones tan básicas como la de gobierno democrático. También revelaron una base de actitudes claramente autoritaria (Ortiz Jiménez y Vanegas Useche, 2001).

Los autores del citado estudio llamaron la atención acerca de varios factores que contribuyeron a este magro resultado: la limitada capacidad de comprensión de lectura de la gran mayoría de los jóvenes colombianos; relacionado con este hecho, las limitaciones materiales de los hogares de donde provienen muchos estudiantes: sólo un 7 \% reportó que en su casa había 200 o más libros; así como la inadecuada preparación de sus maestros, un $40 \%$ de los cuales escogió la opción no sabe o no responde, cuando se les preguntó qué es la educación cívica. Con el fin de remediar esta situación, cinco años después, el Ministerio de Educación Nacional de Colombia (2006) estableció unos lineamientos acerca de la educación cívica y la pedagogía constitucional que son encomiables. El Ministerio de Educación Nacional de Colombia (2006) puso su énfasis no en "los contenidos que se deben enseñar, sino en las competencias que se deben desarrollar para transformar la acción diaria": comunicativas, cognitivas, emocionales e integradoras. Estas competencias deben, a su vez, desarrollarse en tres dimensiones: convivencia y paz; participación y responsabilidad democrática; pluralidad, identidad y valoración de las diferencias ${ }^{7}$.

Con el fin de tener indicadores acerca de la adquisición de esas competencias, desde el 2012 la prueba de conocimientos estatal Saber 11 incorpora una batería de preguntas acerca de la vida cívica. Un reciente estudio de Nancy

\footnotetext{
Alejandra Ariza (2007) sostiene que "los documentos [del Ministerio de Educación Nacional] que orientan la formación ciudadana en el nivel básico y a escala nacional privilegian la concepción liberal de democracia, restringiendo la formación ciudadana a la instrucción del individuo en los derechos fundamentales y en los valores para la convivencia" (p. 160). Yo estoy en desacuerdo. Los lineamientos del Ministerio de Educación (2006) establecen una serie de metas en la adquisición de competencias que incluyen el desarrollo de la capacidad para reconocer los conflictos, tomar en cuenta las perspectivas de los involucrados y participar en la vida pública, no sólo en el ámbito electoral. Estos lineamientos contrastan con la política del presidente con el tinte autoritario más marcado que hemos tenido durante los últimos treinta años.
} 
Palacios y Miguel Armando Rodríguez (2019) muestra que estamos muy lejos de alcanzar los objetivos que se propuso el Ministerio de Educación Nacional hace quince años. Palacios y Rodríguez examinaron los resultados obtenidos por doscientos sesenta y cuatro estudiantes de tres tipos de instituciones escolares en la ciudad de Ibagué y, además, los encuestaron. A pesar de que están por encima de la media nacional, la gran mayoría tiene un nivel de cultura cívica muy limitada. Sólo unos cuantos tienen el conocimiento suficiente para participar en la vida pública y demandar rendición de cuentas a las autoridades. Lo peor es que, según lo reportan los propios estudiantes, este conocimiento se basa principalmente en cuestionarios de preparación para la prueba estatal, no en una asimilación de los contenidos básicos fundado realmente en el desarrollo de sus competencias cívicas.

Aunque por mandato de la propia Constitución esta debe ser enseñada en todos los establecimientos educativos, las universidades están muy lejos de corregir el pronunciado déficit de cultura cívica de las escuelas y colegios. Dos estudios acerca del conocimiento de la Constitución que tienen estudiantes de pregrado de psicología (Romero Espinosa y Mejía Vélez, 2012) y de ingeniería (Romero Espinosa y Mejía Vélez, 2013) ponen de presente la precaria formación que tienen muchos universitarios, la aversión hacia la participación política y la aprobación de prácticas clientelistas y corruptas. Además, hay muchas universidades en las cuales, con excepción de las facultades de derecho y los departamentos de ciencia política, no se enseña la Constitución. Para decirlo lapidariamente, el sistema universitario está de espaldas a la enseñanza de la Constitución. Quizá la evidencia más elocuente ello es el reciente libro La educación en Colombia de Moisés Wasserman (2021, pp. 46-51), exrector de la Universidad Nacional de Colombia. En las páginas que dedica al régimen normativo de la educación, Wasserman omite toda referencia a los artículos 41, 45 y 68 de la Constitución (1991). Wasserman, no sobra resaltarlo, es un intelectual bastante reconocido, quien publica una columna semanal en uno de los principales periódicos de Colombia, el diario El Tiempo. Si este es el caso del exrector Wasserman, ¿qué podemos esperar de muchos educadores de Colombia?

En una tesis de grado dedicada al tema de la pedagogía constitucional, los autores describen el rico entramado de instituciones que tienen responsabilidad con la difusión y enseñanza de la Constitución (Arias Díaz y Carrillo Barahona, 2015, pp. 93-101). En la cúspide de este sistema está la Corte Constitucional. De acuerdo con el planteamiento de John Rawls (1993, pp. 231-240) en su libro Political Liberalism, el tribunal constitucional de cada país es el parangón del ejercicio de la razón pública. Rawls destaca que ese tribunal es probablemente la única rama del Estado que realiza sus deliberaciones solamente con base en esa razón pública. En efecto, a diferencia de los magistrados 
del tribunal constitucional, los votantes y los representantes popularmente elegidos están usualmente exentos de justificar sus decisiones con apego exclusivo a los valores y principios constitucionales comunes.

Uno podría decir que la Corte Constitucional colombiana actúa del modo propuesto por Rawls. Sin embargo, este tribunal está muy lejos del planteamiento rawlsiano según el cual sus juicios hacen más vívida y vigorosa la razón pública en el foro político. Muchas decisiones de la Corte son excesivamente largas y están redactadas en un lenguaje abstruso, de difícil acceso para la mayor parte de la ciudadanía. La Corte muchas veces se explaya en disquisiciones y repeticiones barrocas, alejadas del propósito de aclararle a la ciudadanía qué valores y principios están en juego en cada caso, cuáles son las soluciones posibles a los conflictos que tiene que resolver y porqué la solución escogida por ese tribunal es, a juicio de la mayoría de sus miembros, la más razonable. Los magistrados y sus asistentes parecen más interesados en persuadir a un público de expertos que en ilustrar a la opinión pública acerca de la aplicación de la Constitución (1991). La suya es entonces una pedagogía pedante y abstrusa, apropiada para una sociedad autoritaria que valora la impostura, no para una sociedad democrática que aprecia la rectitud y la claridad. Otro tanto se puede decir de los demás altos tribunales que remedan la pedantería de la Corte Constitucional con su vocabulario pomposo y sus largas y tortuosas frases.

\section{Vaciamiento electoral de la democracia y reproducción de patrones autoritarios}

El limitado conocimiento que tiene la mayoría de los estudiantes de la Constitución (1991) tiene mucho que ver con su limitada experiencia política en los establecimientos educativos. El contraste entre sus competencias básicas y su competencia política es diciente. A pesar del método tradicional de enseñanza, de todos modos, muchos estudiantes practican lo que aprenden. Lo hacen todos los días al echar mano de su capacidad básica de lectura, escritura y aritmética. Con los valores políticos sucede algo totalmente distinto. Esos valores siguen separados de su experiencia. No hay nada en su vida cotidiana que los acerque a un saber hacer práctico-político. Lo más grave, quizá, puede ser el hecho de que el intento de acercar la escuela a la experiencia democrática ha sido totalmente inadecuado. En contravía del modelo participativo de la Constitución (1991) y de la visión de la ciudadanía como una comunidad de agentes que continuamente aprenden, las instituciones creadas por la ley para fomentar valores democráticos en la escuela han terminado por reducirlos a una mera experiencia electoral. Este problema fue identificado elocuentemente hace dos décadas en uno de los primeros estudios sobre la democracia en la escuela. 
En contraste con la idea de democracia como la construcción colectiva de un nuevo orden social, como una forma de ver el mundo, y como una democracia participativa, lo que puede estar sucediendo en muchos lugares de Colombia es que la democracia se está reduciendo a uno de sus mecanismos, es decir, el voto electoral y las elecciones representativas.

Cuando el año escolar empieza, las escuelas eligen un gobierno escolar y un personero estudiantil. Estas elecciones se conciben en muchos casos como una "simulación" de la característica del voto de las democracias representativas, y no como una posibilidad de construir colectivamente un orden escolar y de crear un gobierno escolar participativo y una comunidad educativa cimentada en fines y perspectivas comunes.

Se puede ver que el problema que la Constitución en 1991 trató de solucionar, se está reproduciendo en las escuelas: falta de control y responsabilidad entre los electores y los elegidos; falta de equilibrio en los poderes; estructuras de poder burocratizadas y centralizadas; y una aproximación formal al manejo de los derechos de los estudiantes. Generalmente, el personero estudiantil es sólo una figura formal en las escuelas de secundaria. La mayoría de las veces el personero no puede ejercer adecuadamente sus funciones en defensa de los derechos de los estudiantes porque los estudiantes no están informados, los profesores no están abiertos a esto, y las organizaciones estudiantiles son poco desarrolladas. (Rodríguez Rueda, 1999, p. 189)

Desafortunadamente, la noción de democracia con la cual se familiarizan los estudiantes en la educación básica y media sigue siendo la de una competencia electoral, disociada de su experiencia cotidiana. La democracia, así concebida, ha quedado reducida a un certamen ritual que sirve desde temprano para despertar el afán narcisista de reconocimiento. No hay en esta práctica atisbos siquiera de un proceso de construcción colectiva de alternativas acerca de problemas comunes. Esta misma situación se reproduce en muchas universidades donde hasta hace poco tiempo ha habido rectorías o decanaturas ocupadas por personas que duran toda la vida en los cargos de dirección. Estos rectores y decanos sempiternos, incluso si son déspotas ilustrados, son déspotas, y con sus dichos y acciones difunden una concepción autoritaria de la organización educativa que termina siendo interiorizada como la forma normal de la vida universitaria ${ }^{8}$.

Con respecto a estas instituciones, la realización de elecciones en las cuales los estudiantes y profesores votan, pero no deciden, es de alguna forma un progreso. Aunque un consejo superior, encargado de tomar la decisión, puede apartarse por completo del resultado electoral, estas elecciones no decisivas

8 Un ejemplo revelador de este fenómeno es la siguiente descripción de la organización interna de una universidad privada muy prestigiosa en Colombia. "[E]n alguna ocasión, en el despacho de la rectoría, el maestro Hinestrosa me tomó del codo y me condujo a la ventana de su oficina, desde la que se veía en ese momento la construcción de los bloques D y E, para decirme, palabras más, palabras menos: 'El Externado es como un ejército romano, que se constituye por legiones, que son los departamentos de derecho y las decanaturas de las otras facultades'" (Velandia, 2021). 
permiten al menos registrar la voz de la comunidad universitaria. Se trata, sin embargo, para decirlo oximorónicamente, de una auténtica simulación democrática. Uno no puede dejar de notar que, en universidades donde los miembros de la comunidad educativa votan, pero no deciden, como la Universidad Nacional, la tasa de participación de los estudiantes es incluso más baja que la tasa de participación electoral a nivel nacional ${ }^{9}$, que es una de las más bajas del mundo ${ }^{10}$.

En un debate en la Cámara de los Comunes del Reino Unido, el diputado Tony Benn (UK Parliament, 1998, columna 685) propuso un test para saber si uno vive en un sistema democrático. Según Benn, uno debería hacer las siguientes cinco preguntas a todas las personas poderosas: "¿qué clase de poder tiene?, ¿dónde lo obtuvo?, ¿en interés de quién lo ejerce?, ¿a quién le tiene que rendir cuentas? y ¿cómo lo puede remover del cargo?". Estas preguntas desbordan completamente el marco electorero con el cual se concibieron las prácticas democráticas en los establecimientos educativos. Antes bien, ponen en evidencia que las instituciones educativas funcionan sobre una base autoritaria, tal y como lo resaltaré en las siguientes secciones.

\section{Clientelismo y gremialismo en la educación}

El vaciamiento electorero de la democracia tiene su correlato en otro fenómeno observado en muchos establecimientos educativos: la ausencia de una carrera docente y, donde ella existe, su desfiguramiento por cuenta de prácticas gremialistas y de espíritu de cuerpo, contrarias a todo sentido meritocrático. De este modo, muchos establecimientos de enseñanza, en lugar de ser un modelo a imitar en otros ámbitos, son apenas un espejo en el cual la sociedad ve reproducidas las prácticas que muchos encuentran cuestionables en la vida pública. En efecto, así como uno de los graves problemas del sistema político colombiano ha sido la falta de voluntad de los partidos políticos para liberar el servicio público de la interferencia clientelista, la sociedad colombiana ha permitido que en muchos establecimientos privados de enseñanza impere la arbitrariedad en los procesos de vinculación, permanencia y despido del profesorado.

En la esfera estatal, los directivos de muchas entidades vinculan a un gran número de empleados públicos mediante contratos con los cuales se les niega el

En efecto, en las votaciones de 2012, esa tasa fue del 19,6\%; en el 2015, 30,6 \%; y en el 2018, 24,8 \%.

10 Cabe agregar que, en algunas universidades públicas, el efecto de establecer elecciones para escoger al rector ha tenido un efecto siniestro. Como lo señala Daniel Mera (2021) en una reciente columna, hay universidades públicas donde los candidatos hacen campaña prometiendo dádivas al personal docente y administrativo que son patentemente irrazonables. Esto explica situaciones como la de la Universidad del Chocó, donde un acuerdo entre el sindicato de profesores y las directivas ha dado lugar a que los docentes de esta institución tengan los salarios más altos en el país, a pesar de que sus estudiantes ocupan "el último lugar en las pruebas Saber Pro en el 2019, el puesto 249 de las 249 instituciones universitarias evaluadas" (Mosquera, 2020). 
carácter de tales. A diferencia de los empleados públicos propiamente dichos, que hacen parte de la carrera administrativa, estos empleados públicos irregulares están a merced de los patrones que controlan las redes de clientela, redes a las cuales se adscriben esos empleados para acceder y conservar sus empleos. La inadecuada y limitada implementación de la carrera administrativa en la burocracia estatal tiene su correlato en la ausencia de una verdadera carrera docente, que proteja a los profesores de la arbitrariedad de las redes de clientela privada que operan en muchos establecimientos de enseñanza.

La Ley General de Educación 115 (1994) establece una carrera y un escalafón docente únicamente para los establecimientos públicos de enseñanza. No dice nada al respecto de los establecimientos privados. Estos últimos se amparan en el artículo 101 del Código Sustantivo del Trabajo de acuerdo con el cual el contrato de trabajo "se entiende celebrado por el año escolar". Si bien la Corte Constitucional (Sentencia C-483/95, 1995) declaró inexequible la disposición que permitía suscribir contratos por tiempo menor, dejó en pie la referida disposición negando en la práctica la defensa que hizo la misma Corte de la estabilidad laboral como derecho mínimo fundamental de los trabajadores. Así las cosas, en Colombia es perfectamente legal que un establecimiento de enseñanza contrate sucesivamente a un docente cada año, manteniéndolo en la incertidumbre acerca de la continuidad de su relación laboral. Tan grave como lo anterior es la autonomía que muchas personas le reconocen a los establecimientos privados de enseñanza para despedir a un docente, cuando le plazca, a pesar de estar vinculado con un contrato a término indefinido ${ }^{11 .}$

La carrera docente, donde existe, protege al profesorado de despidos arbitrarios. Esta protección es la base más firme de la libertad de cátedra y uno de los pilares de la democracia en los establecimientos de enseñanza. Ningún efecto real tiene los principios constitucionales, si las instituciones legales le reconocen a los directivos de escuelas, colegios y universidades una autonomía que los anula. Es obvio que un profesor que depende de que las directivas renueven su vinculación cada año interiorizará cualquier expresión de censura de esas directivas con el fin de conservar su empleo. Con mayor razón, interiorizará su frustración ante cualquier situación irregular y se abstendrá de demandar transparencia y rendición de cuentas a esas mismas directivas. Parafraseando a Tony Benn, si uno no le puede preguntar a las directivas de un plantel educativo ¿a quién le tienen que rendir cuentas? y ¿cómo se las puede remover de su cargo?, ¿puede uno esperar que en ese plantel echen raíces valores y prácticas democráticos?

11 Ejemplo de ello es la opinión emitida por Gustavo Duncan (2020) en su columna en el diario El Tiempo a propósito del despido de un profesor de la Universidad de la Sabana. Según Duncan esa universidad estaba "en su derecho de no renovar el contrato de un profesor muy reconocido, pero le debe una explicación a la comunidad académica" (la cursiva es mía). 
La carrera docente es un componente fundamental de la democratización de los establecimientos educativos. Sin embargo, debería funcionar permitiendo la continua evaluación de los profesores, de modo que su permanencia y ascenso esté condicionada al cabal cumplimiento de sus deberes. Infortunadamente, este no es el caso en muchas instituciones públicas. El sindicato de docentes que trabajan en establecimientos públicos se ha opuesto reiteradamente a un sistema de evaluación que permita identificar qué profesores deben mejorar su desempeño pedagógico y cuáles deberían ser retirados de la carrera (Camargo, 2019). A la luz de los pobres resultados de los estudiantes colombianos en pruebas internacionales, esta oposición es bastante irrazonable. Es claro que hay graves deficiencias en la enseñanza y en el aprendizaje que, si bien no son imputables a los profesores, sí demandan de estos un mayor compromiso en su corrección. En lugar de ello, el sindicato de docentes ha cerrado filas para asegurar la permanencia en el cargo de todos sus miembros, sin ofrecer alternativas para el mejoramiento del desempeño pedagógico. Muchos profesores han participado en protestas orientadas a impedir la puesta en vigor de sistemas de evaluación más exigentes. Esto no es participación democrática sino una distorsión de la misma; es gremialismo y espíritu de cuerpo puro y duro, materializado en un inaceptable poder de veto sobre un componente de las políticas educativas.

En el ámbito universitario las cosas no son mejores. Hay muchos centros de enseñanza donde no se realizan evaluaciones de los profesores por parte de los estudiantes. En otros, esas evaluaciones son voluntarias, pero son pocos los estudiantes que las realizan pues usualmente no tienen ninguna consecuencia. Otra sería la situación, si las directivas académicas tomaran nota de las quejas y reclamos de los estudiantes en esas evaluaciones. Desde luego, no todas son razonables. Sin embargo, las universidades podrían evitar muchos casos de acoso sexual y de maltrato cuya ocurrencia ya ha empezado a ocupar las páginas de los periódicos (Jiménez et al., 2017), si hubiese un espacio en el cual la comunidad académica pudiese tomar medidas respecto de los docentes que abusan de su autoridad. Ese espacio sería una forma de hacer efectiva la rendición de cuentas, una práctica democrática sin la cual los valores democráticos no pueden echar raíces.

\section{Los lazos secundordiales y la endogamia universitaria}

En la década de los sesenta del siglo pasado, el antropólogo Clifford Geertz (1973) hizo una contribución decisiva a la comprensión del funcionamiento político de muchos estados que alcanzaron su independencia después de la Segunda Guerra Mundial. Según Geertz (1973), el carácter pluriétnico y plurirreligioso de las nuevas unidades políticas basadas en la competencia electoral dio lugar a la afirmación de lazos primordiales a expensa de los lazos cívicos, afectando 
negativamente el funcionamiento de las nuevas instituciones. El lazo primordial es el que está basado en un apego fundado en los lazos de sangre y el parentesco, y también en la proximidad que muchos individuos perciben en ciertos contextos como fundamental para la continuidad de su existencia: el tener una misma lengua y unas mismas tradiciones o unas mismas creencias religiosas. La independencia política no contribuyó a aminorar la intensidad de esos lazos. Antes bien, donde grupos diversos tenían que competir por el control del poder de las instituciones públicas, la afirmación de esos lazos se convirtió en un recurso de la lucha política. De este modo, en vez de diluirse en favor del vínculo cívico universal de la ciudadanía, los lazos primordiales se convirtieron en el vínculo más importante en la vida de muchos individuos.

Un fenómeno similar ocurre en la sociedad colombiana, pero con los lazos de segundo orden. En Colombia no hay divisiones étnicas o religiosas tan intensas que motiven a los individuos a afirmar un vínculo primordial con una comunidad superior a la comunidad política. No obstante, durante el período conocido como La Violencia, la división partidista alcanzó una intensidad similar: el lazo con el partido prevaleció completamente sobre el lazo ciudadano (Perea, 1996). El Frente Nacional, un acuerdo consociacional entre los partidos Liberal y Conservador, desvaneció la intensidad del primero, pero no consolidó el último. En una sociedad secularizada y fuertemente orientada hacia valores materiales, pero con una gran desigualdad y una estructura autoritaria, los lazos secundordiales han adquirido una gran relevancia. Estos son los lazos que se forman más allá de los grupos primarios como la familia o la vecindad (Cooley, 1909, p. 23; Shils, 1957), en instituciones como las universidades y las asociaciones profesionales. No debería sorprendernos que los lazos secundordiales que se forman en estas instituciones y asociaciones socaven, en lugar de reforzar, los lazos ciudadanos. En efecto, el lazo secundordial por excelencia es la rosca: una red informal cuya pertenencia asegura acceso a cargos, recursos y privilegios de manera exclusiva a los miembros de la red, a cambio de favores recíprocos a los demás miembros y, sobre todo, de la lealtad a quienes ocupan un lugar central en esa red. La rosca se rige por un código similar al de la mafia: entre sus miembros hay un cierto sentido de honorabilidad, que sirve de medio para acuerdos que no tienen nada de honorables. Gracias a las roscas, ocurren fenómenos como el descrito por un profesor de una prestigiosa universidad privada: hay "lagartos y mediocres que tienen cátedras que no merecen, becarios por amiguismo, gastos no justificados, eternos directores de departamento que le han quitado espacio legítimo a varias generaciones" (Estrada, 2020).

En varias universidades de Colombia, hay roscas que han asumido un decidido carácter criminal, dadas las actividades fraudulentas que promueven. Bastaría mencionar sólo un par de casos. En la Universidad del Atlántico, el Comité de 
Asignación y Reconocimiento de Puntaje le otorgó puntos salariales a docentes que publicaron en revistas cuya calidad académica es bastante cuestionable. Entre los beneficiarios de este sistema fraudulento hay un profesor a quien le reconocieron la publicación de más de cuarenta artículos de investigación al año (Observatorio de la Universidad Colombiana, 2021). En otras universidades el fraude es mucho más sofisticado: consiste en el acuerdo con profesores de otras universidades para incrementar artificialmente el número de citas de sus publicaciones con el fin de generar la apariencia de que tienen una relevancia académica de la cual realmente carecen y de ese modo inflar su salario. A este fenómeno se le llama coloquialmente "el carrusel de las publicaciones". Un caso representativo de este fraude es el de los profesores que pertenecen a un grupo de investigación en criminología de la Universidad Católica, del cual es parte el decano de la Facultad de Derecho. Al ser confrontado con la evidencia de esta práctica, el decano se defendió así: "no hay ninguna norma legal que se haya vulnerado, como tampoco ninguna práctica académica malsana" (Observatorio de la Universidad Colombiana, 2021). Es imposible que universidades de este tipo le ofrezcan a la sociedad un modelo de corrección ética que contraste con las prácticas clientelistas que prevalecen en la esfera pública.

En la mayoría de las universidades más prestigiosas del país tanto públicas como privadas ocurre, además, un grave fenómeno de endogamia. Al revisar la hoja de vida de los profesores de facultades y departamentos de larga trayectoria histórica como derecho y economía en la Universidad Nacional, la Universidad de los Andes, la Universidad Javeriana, la Universidad del Rosario y la Universidad Externado de Colombia, uno encuentra que la mayoría de los profesores hizo su pregrado en esa misma universidad. La endogamia, por meritocrática que sea, tiene bastantes efectos indeseables en la sociedad: tiende a reproducir esquemas de pensamiento similares, reduciendo la posibilidad de adoptar ideas nuevas, del mismo modo que la endogamia genética reduce la posibilidad de que un grupo incorpore genes nuevos. Esto ha motivado a los gobiernos de varios países a tomar medidas orientadas a combatirla (Horta y Yudkevich, 2016). Otro de los efectos indeseables de la endogamia académica es la consolidación de redes relativamente homogéneas que limitan la oportunidad de personas de otra proveniencia de acceder a altos cargos directivos en las instituciones estatales. El estudio realizado por Roth y Robayo (2015) sobre el perfil sociodemográfico quienes ocupan las posiciones en el alto gobierno mostró que el 54 \% provenía de dos universidades privadas: los Andes y la Javeriana ${ }^{12}$. En contraste con esta realidad, conviene tomar en cuenta que la mayor diversidad en la alta burocracia no sólo aumenta la legitimidad del Estado. Por mor de esa

Este es un fenómeno cuya ocurrencia ha sido estudiada en otros países latinoamericanos como Brasil y Chile (Quaresma y Villalobos, 2018). 
misma diversidad, la alta burocracia puede incorporar nuevas ideas que mejora sustancialmente la formulación e implementación de las políticas públicas.

\section{El currículo oculto del sistema educativo}

Uno de los conceptos más útiles para comprender el limitado efecto que tiene la enseñanza de la Constitución en el actual sistema educativo, y que seguiría teniendo si este no es reformado, es el del currículo oculto. Este concepto dirige nuestra atención a lo siguiente: "a la par con el currículo académico públicamente reconocido, hay una serie de actitudes que se transmiten en el centro de enseñanza, a propósito o de manera inconsciente, y que no son reconocidas abiertamente en dicho centro, a menos que los estudiantes las hagan conscientes" (Martin, 1983, p. 131)13. Esas actitudes están en correspondencia, por así decirlo, con las actitudes que demandan otros sistemas sociales en el desempeño de diversos roles. Por ejemplo, las actitudes adquiridas en las facultades de derecho están en correspondencia con lo que se espera de los abogados en el sistema judicial. Esta es la razón por la cual el currículo oculto es visto como el aprendizaje en una esfera micro de lo que se espera en la esfera macro de la sociedad (Vallance, 1983, p. 11).

¿Cuál es el currículo oculto vigente en el sistema educativo colombiano? Martin (1983, p. 130) llama la atención al hecho de que ningún sistema tiene uno y no más que uno; cada centro educativo tiene el suyo, el cual refleja la particular configuración de poder que se da entre directivas, profesores, estudiantes y personal administrativo. No obstante, a riesgo de incurrir en la falacia de la generalización abusiva, podría decirse que en muchos establecimientos educativos

[L]o que los alumnos irán aprendiendo por el camino, de manera implícita pero contundente, es que las posibilidades para el diálogo genuino son bastante limitadas, que no se puede confiar en la autoridad porque ella es arbitraria, que el orden se mantiene en realidad a la fuerza, que hay que morderse la lengua y, llegado el caso, que hay que 'comer callao'. (Gómez Albarello, 2018, pp. 316-317)

Es un juicioso resumen lo dicho hasta aquí. Donde la democracia ha sido vaciada de contenido y reducida a una pura experiencia electorera; donde prevalecen el clientelismo y el espíritu de cuerpo, los lazos secundordiales y la reproducción endogámica es virtualmente imposible que se consoliden prácticas democráticas genuinas tales como la demanda de transparencia y de rendición de cuentas. Esta

13 Otras definiciones más o menos concordantes del mismo concepto son las siguientes: "son las consecuencias no académicas pero educacionalmente significativas de la instrucción académica que ocurren sistemáticamente, pero que no se hacen explícitas en ningún nivel de la justificación de la educación" (Vallance, 1983, p. 11) y son "las normas, valores y creencias no explícitas que se le transmiten a los estudiantes mediante la estructura de sentido subyacente tanto al contenido formal como a las relaciones sociales que tienen lugar en la escuela y en la experiencia en el salón de clase" (Giroux y Penna, 1983, p. 102). 
observación permite resolver la aparente contradicción que el periodista Juan Pablo Calvás planteó acerca de la corrupción en Colombia. Este nota el hecho de que "aunque le achacamos todos los problemas a la falta de educación, son muchas veces los más educados quienes se aprovechan de su posición social para sacarle el cuerpo a la ley" (2018). Sería apresurado concluir que los corruptos se corrompieron en las escuelas, colegios y universidades, en el sentido de que fue en sus años de estudio formal que aprendieron a saltarse las normas. La conexión entre el funcionamiento de los establecimientos educativos y la corrupción es más sutil. En este sistema educativo autoritario, lo que se aprende es a no demandar responsabilidad, lo cual le deja el campo libre a quienes tienen los recursos para circunvalar el cumplimiento de la ley. No todos se atreven porque les falta audacia, pero donde la ambición, la audacia y los recursos se juntan, el efecto es el mismo. La ausencia de una sociedad capaz de demandar responsabilidad les deja abierto el camino. Este es el currículo oculto que socava la vida cívica en Colombia.

\section{El sistema educativo y los malos ejemplos}

En sus Discursos sobre la primera década de Tito Livio (libro III, cap. 22), Nicolás Maquiavelo (2016, p. 371) afirma que "si una república tuviera la suerte de que surgieran en su seno quienes renuevan las leyes con su ejemplo, impidiéndole que avance hacia su ruina y retrotrayéndola a sus orígenes, esta sería perpetua". La tesis de Maquiavelo se basa en varias proposiciones que el florentino enuncia a lo largo de su obra. En el libro III, capítulo 29, Maquiavelo refrenda la opinión de Lorenzo de Medici según la cual lo que hace un señor termina siendo imitado por muchos pues la mirada de estos siempre está puesta en aquel. La eficacia del ejemplo puede tener su causa en varios mecanismos. Uno de ellos, el más básico, referido por Piaget (1995) es que uno interioriza la escala de valores de aquellos a quienes les reconoce autoridad. Otro más concierne al efecto moderador del ejemplo sobre la ambición de aquellos que quieren ascender en la escala jerárquica de la sociedad: para ser aceptados por quienes están en posiciones más altas, es preciso comportarse como estos lo hacen.

Un mecanismo adicional tiene que ver con la cualidad práctica del ejemplo. La enunciación de un valor se convierte en un modelo, cuando una persona lo materializa con sus acciones. Ese modelo se convierte en un saber-hacer, que quienes siguen el ejemplo reproducen luego en otras situaciones. De aquí se deriva la segunda proposición en la cual se basa la tesis de Maquiavelo: para que las leyes tengan algún efecto, es necesario que haya ciudadanos virtuosos dispuestos a hacerlas cumplir contra quienes las transgreden (libro III, cap. 1). Mas no es sólo el cumplimiento de la ley. Maquiavelo (2016), agrega, 
[E]l renacer de una comunidad política puede deberse enteramente a la virtù de un solo hombre sin que ninguna ley lo estimule a realizar actos ejemplares, pues la virtù de hombres excepcionales tiene tanto prestigio y es un ejemplo tan eficaz, que los hombres buenos desean imitarlos y los malos se avergüenzan de llevar una vida tan contraria a la suya. (p. 307)

La tercera proposición en la cual se basa la tesis de Maquiavelo es que el ejemplo que renueva la república es aquel mediante el cual los ciudadanos expresan su profunda devoción hacia el bien común, incluso si ello implica hacer grandes sacrificios. En el libro II, capítulo 2, Maquiavelo afirma que lo que hace grande a la ciudad es la tutela del bien público; en el libro III, capítulo 22, sostiene que el mejor modo de actuación de un ciudadano es volcarse hacia el bien público, sin traza de ambición privada y en el mismo libro III, capítulo 3, Maquiavelo encomia la acción de Bruto de juzgar, condenar a muerte a sus hijos y ejecutarlos por haber conspirado contra la república recién establecida. Según Maquiavelo, este sacrificio era necesario para grabar en la memoria el castigo a los enemigos del nuevo régimen. Esta acción contrasta con la de Girolamo Savonarola de promover la adopción de una ley y luego negarse a cumplirla pues de ese modo puso en evidencia su partidismo y arruinó su reputación (libro I, cap. 45). Una cuarta proposición, que suplementa las anteriores, concierne a la importancia que tiene para la república la abundancia de hombres virtuosos. Al ser muchos en Roma, se controlaban mutuamente. El ejemplo de cada uno reforzaba el de los demás, inhibiendo su ambición. Esto, a su vez, redundaba en una mayor confianza del pueblo en sus gobernantes (libro I, cap. 30).

Esta digresión tiene como propósito resaltar el hecho de que la educación democrática no es una tarea que se agota en la escuela. Los líderes públicos, no sólo los gobernantes, cumplen una función pedagógica continua. Cuando lo hacen virtuosamente, renuevan y vivifican los valores que le dan legitimidad al régimen. Cuando no, propagan en el pueblo sus vicios14. En una sociedad autoritaria y corrupta, los establecimientos educativos, a los que les corresponde enseñar la Constitución (1991), tienen la carga de contrarrestar los anti-valores de los líderes públicos, cuando actúan en contravía de los principios democráticos. Sin embargo, es apenas comprensible que al final la enseñanza cívica termine socavada por su mal ejemplo. La mención a algunos hechos y dichos de los presidentes de Colombia, luego de promulgada la Constitución (1991), permite entender porqué la juventud de este país tiende a refrendar prácticas autoritarias y corruptas.

En efecto, luego de que estallara el escándalo de entrada de dineros del narcotráfico a su campaña, el entonces presidente Ernesto Samper, se negó

${ }_{14}$ De ahí que Maquiavelo afirme que las faltas de los pueblos tienen su origen en los príncipes (Discursos, libro III, cap. 29). 
a asumir cualquier responsabilidad por lo sucedido. Su defensa, "si se recibió plata de narcos, fue a mis espaldas" (El Tiempo, 1995), un verdadero modelo de negación plausible ha hecho carrera como un artilugio retórico para evadir las demandas de rendición de cuentas. Álvaro Uribe, por su parte, hizo de la descalificación de la justicia, de sus adversarios y, en general, de todas las personas que lo cuestionan, una forma habitual de responder a todo cuestionamiento. Sus seguidores, desafortunadamente, han interiorizado esta actitud y reproducen comportamientos en las antípodas de una verdadera cultura civil. La lista de pronunciamientos y acciones que encarnan antivalores constitucionales es, por supuesto, mucho más larga.

El sistema educativo debería ser un lugar en el cual estudiantes y profesores pudiesen someter a escrutinio los malos ejemplos de los líderes públicos. El contraste entre los valores y los principios constitucionales, y esos malos ejemplos debería suscitar al menos una reflexión entre los educadores y los educandos, y eventualmente una acción de rechazo ciudadano. Si bien esta demanda es loable, en las actuales condiciones, no parece plausible que se haga efectiva. Hay un obstáculo formidable que el sistema educativo tendría que superar: es el que proviene de su propia organización y prácticas internas. Si los establecimientos educativos tienen una estructura autoritaria, reproducen prácticas clientelistas y vacían la democracia de su verdadero contenido, es muy difícil que estos establecimientos faciliten el cuestionamiento de los malos ejemplos de los líderes públicos.

La discusión acerca de los malos ejemplos no se agota en los que provienen de la vida pública. Los establecimientos educativos deberían tener, además, espacios en los cuales pudieran abordarse los malos ejemplos, cuando ellos provienen de la familia. A este respecto, conviene tomar nota del hallazgo de Myriam Jimeno e Ismael Roldán (1996) acerca de la desobediencia como uno de los detonantes de la violencia intrafamiliar. Muchos padres demandan obediencia frente a tareas excesivas y órdenes absurdas, y recurren a la violencia, cuando perciben que son desobedecidos. Esa violencia es racionalizada de distintas formas, por ejemplo, en función de atributos personales del agresor ("irascible, nervioso, enfermo" [p. 118]). El tema es que el recurso continuo a la violencia se convierte "en un aprendizaje establecido, en un código cognitivo que induce a la pasividad y a la resignación, o al empleo de la violencia en futuras situaciones similares" (Jimeno y Roldán, 1996, p. 118). Una escuela autoritaria no está en capacidad de poner en cuestión el autoritarismo de los padres. Lo más probable es que esa escuela reafirme los códigos cognitivos y afectivos autoritarios adquiridos en la familia. Sólo una escuela democrática puede liberar a sus discentes del conjuro de tener que someterse a la violencia o encarnarla para no ser víctima de una agresión. De ahí la urgente tarea de reformar el sistema 
educativo, para que la niñez y la juventud crezcan imbuidas del valor del respeto a los derechos humanos, la paz y la democracia.

\section{Conclusión: cómo hacer democrática la educación y realmente democrática la 'democracia' colombiana}

Un lugar común en la conversación social en Colombia es el planteamiento según el cual reformar la política no solo es muy difícil, si no imposible. Esperar que los políticos actúen distinto, incluso bajo reglas sustancialmente distintas, sería ingenuo. Por esta razón, muchas personas cifran sus esperanzas en la educación de las nuevas generaciones. No obstante, no prestan atención al hecho de que el sistema educativo reproduce en su interior muchas de las prácticas que deploran, por lo cual es aún más ingenuo esperar que la política cambie pues la ciudadanía del futuro no recibirá una educación distinta. Este es precisamente uno de los mayores retos que tenemos: cómo reformar la educación para hacerla más democrática y, de ese modo, contribuir a que la "democracia" colombiana sea realmente democrática.

Uno de los puntos de partida de una futura reforma educativa debería ser el establecimiento de una auténtica carrera docente, donde no la hay, y el establecimiento de un riguroso sistema de evaluación, donde esa carrera ya existe. La carrera docente asegura la independencia del profesorado respecto de los vaivenes y veleidades que puedan tener las directivas de los establecimientos educativos. Le proporciona a cada profesor una base institucional para que pueda demandar transparencia y rendición de cuentas, rompiendo de este modo el efecto de las prácticas autoritarias prevalecientes en la actualidad. A su turno, docentes independientes podrán formar discentes autónomos.

Empero, este cambio no tendría un efecto renovador, si el ingreso y la permanencia en la carrera solidifica los lazos secundordiales existentes. Es preciso romper estos lazos mediante el establecimiento del más riguroso sistema meritocrático. Donde la carrera docente existe, es preciso revisarla a la luz del mismo criterio. De otro modo, esa carrera será un mero botín de los intercambios de redes de clientela, como tal parece ser la situación en muchos establecimientos educativos públicos, donde el profesorado se opone a un sistema de evaluación que penalice el insuficiente desempeño pedagógico. Esta es una situación que tiene que cambiar y para la cual se requiere de mucha voluntad política. En este orden de ideas, el sistema nacional de educación, ciencia y tecnología también debería revisar el sistema de acreditación de las universidades y dar fuertes estímulos a la exogamia académica.

Los establecimientos de enseñanza deberían, además, superar la concepción electorera de la democracia y trabajar en la construcción de instituciones que 
aseguren, de verdad, la participación de la comunidad educativa en la dirección del proceso educativo. Esta participación debería, además, desdoblarse en una práctica pedagógica más flexible, en sintonía con las particularidades del contexto de cada centro educativo y orientada hacia el aprendizaje basado en la experiencia de la libre indagación y el descubrimiento, así como en la concurrencia con los demás, respetuosa y razonable, en el proceso de definición de los problemas y de construcción de las soluciones. Sería equivocado postular un currículo único, lo cual no significa que la educación no haya de estar orientada hacia virtudes comunes. Antes bien, el planteamiento original del Ministerio de Educación de fomentar la adquisición de competencias ciudadanas (comunicativas, cognitivas, emocionales e integradoras) sigue siendo una guía adecuada de la pedagogía democrática que requiere la ciudadanía del futuro.

El gran desafío es identificar el currículo oculto en cada centro educativo que conspira contra la adquisición de esas competencias. En tándem con esta tarea, los centros educativos deberían acometer otra: encontrar el espacio pedagógico para poner en cuestión los malos ejemplos o, dicho de otro modo, el currículo oculto de otras instituciones, que está en contradicción con los valores democráticos. Desde luego, todos estos cambios tienen que ir acompañados de una firme voluntad política de asegurar recursos para la educación de todas las personas de modo que su acceso sea universal y se ajuste al principio constitucional que le ordena al Estado promover "las condiciones para que la igualdad sea real y efectiva" (art. 13,1991) (Gómez Albarello, 2018).

\section{Agradecimientos}

Quisiera agradecer a Doris Santos y Carlos Alberto Paz por valiosas conversaciones que tuve acerca de varios de los planteamientos presentados en este texto, así como a los evaluadores anónimos cuyas observaciones contribuyeron a mejorar la presentación de los argumentos de este texto.

\section{Referencias}

Asamblea Nacional Constituyente. (1991, 13 de junio). Constitución Política de Colombia. Gaceta Constitucional n. ${ }^{\circ} 116$ de 20 de julio de 1991. http://www.secretariasenado.gov.co/senado/basedoc/ constitucion_politica_1991.html

Arias Díaz, S. y Carrillo Barahona, C. (2015). Pedagogía constitucional en colombia: diagnóstico y propuestas para una educación cívica eficaz [tesis de pregrado, Fundación Universitaria Los Libertadores]. Repositorio institucional. https://repository.libertadores.edu.co/handle/11371/174

Ariza, A. (2007). Democracias, ciudadanías y formación ciudadana: una aproximación. Revista de Estudios Sociales (27), 150-163. https://doi.org/10.7440/res27.2007.10

Bowles, S. y Gintis, H. (1987). Democracy \& Capitalism: Property, Community, and the Contradictions of Modern Social Thought. Basic Books. 
Calvás, J. (2018, 13 de febrero). La mala educación. El Tiempo. https://bit.ly/2UgCXXD

Camargo, C. (2019). Pertinencia de la evaluación de carácter diagnóstico formativa para los docentes del Colegio Instituto Técnico Distrital Julio Flórez Localidad de Suba [tesis de maestría, Universidad Externado de Colombia]. Biblioteca digital. https://bdigital.uexternado.edu.co/handle/001/1573

Cepeda, M. (1993). La constituyente por dentro: mitos y realidades. Presidencia de la República.

Cooley, C. (1909). Social organization: a study of the social mind. Charles Scriber's Sons.

Corte Constitucional. (1995, 30 de octubre). Sentencia C-483/95 (José Gregorio Hernández Galindo, M. P.). https://bit.ly/39xv0BG

De Salisbury, J. (1990 [1159]). Policraticus: of the frivolities of courtiers and the footprints of philosophers. Cambridge University Press.

Dewey, J. (1916). Democracy and education. The Macmillan Company.

Dugas, J. (comp.). (1993). La Constitución de 1991: ¿un pacto político viable? Universidad de los Andes.

Duncan, G. (2020, 22 de diciembre). La libertad cuesta. El Tiempo. https://bit.ly/3gCDbkB

El Tiempo, (1995, 28 de julio). Si se recibió plata de narcos, fue a mis espaldas: Samper. El Tiempo. https:// www.eltiempo.com/archivo/documento/MAM-375661

Estrada, J. (2020, 15 de junio). No te lo puedo creer. El Radical. https://elradical.info/no-te-lo-puedo-creer/

Geertz, C. (1973). The integrative revolution: primordial sentiments and civil politics in the new states. En C. Geertz (ed.), The Interpretation of Cultures (pp. 255-310). Basic Books.

Giroux, H. y Penna, A. (1983). Social education in the classroom: the dynamics of the Hidden Curriculum. En H. Giroux y D. Purpel (eds.), Hidden Curriculum and Moral Education: Deception or Discovery? (pp. 100-121). McCutchan Pub Corp.

Giroux, H. y Purpel, D. (eds). (1983). Hidden Curriculum and moral education: deception or discovery? McCutchan Publishing Corporation.

Gómez Albarello, J. (2018). ¿Una paz maleducada e insostenible? Cómo la política educativa del Estado aleja a Colombia de la justicia, la democracia y la paz. En M. García Villegas (ed.), ¿Cómo salvar a Colombia? 25 ideas para reparar el futuro (pp. 307-324). Ariel.

Gómez Albarello, J. (2019). La apariencia 'democrática' de la Constitución de 1991: crisis y futuro de la representación política en Colombia y en el mundo. Análisis Político, 32(96), 103-121. https://doi. org/10.15446/anpol.v32n96.83753

Habermas, J. (1989). La soberanía popular como procedimiento. Cuadernos Políticos (57), 53-69. https:// bit.ly/3iST47N

Holmes, S. (1995). Passions and Constraints: on the theory of liberal democracy. University of Chicago Press.

Honneth, A. (2013). La educación y el espacio público democrático: Un capítulo descuidado en la Filosofía política. Isegoría, (49), 377-395. https://doi.org/10.3989/isegoria.2013.049.01

Horta, H. y Yudkevich, M. (2016). The role of academic inbreeding in developing higher education systems: Challenges and possible solutions. Technological Forecasting and Social Change, (113B), 363-372. https://doi.org/10.1016/j.techfore.2015.06.039 
Jiménez, C., Tapia, T., Cruz, N. y Vice Colombia. (2017). La violencia sexual sí existe en universidades de Colombia. Connectas. https://bit.ly/3yqPmHh

Jimeno, M. y Roldan, I. (1996) Las sombras arbitrarias. Violencia y autoridad en Colombia. Editorial Universidad Nacional de Colombia.

Luhmann, N. (1993). Teoría política del Estado de Bienestar. Alianza Editorial.

Macpherson, C. (1977). The life and times of liberal democracy. Oxford University Press.

MacWilliams, M. (2016, 17 de enero). The one weird trait that predicts whether you're a Trump supporter. Politico Magazine. https://politi.co/2SMMDJ1

Maquiavelo, N. (2016). Discursos sobre la Primera Década de Tito Livio. Akal.

Martin, J. (1983). What should do with a hidden curriculum when we find one? En H. Giroux y D. Purpel (eds.), Hidden Curriculum and Moral Education: Deception or Discovery? (pp. 122-141). McCutchan Pub Corp.

Medina Palacios, A., Moreno Mosquera, G., Rosero López, J. y García Mosquera, R. (2016). La investigación como estrategia para el mejoramiento de la convivencia escolar y la construcción de ciudadanía. Ciencias Sociales y Educación, 5(10), 101-115. https://doi.org/10.22395/csye.v5n10a4

Mera, D. (2021, 28 de febrero). Desgobierno de las universidades públicas. El Espectador. https://bit. ly/3daIsOj

Ministerio de Educación Nacional. (2006). Estándares básicos en competencias ciudadanas: formar para la ciudadanía sí es posible. Ministerio de Educación Nacional.

Mosquera, J. (2020, 4 de mayo). ¿Una monarquía hereditaria en la Universidad del Chocó? Las 2 Orillas. https://bit.ly/3gDcc8i

Observatorio de la Universidad Colombiana. (2021, 3 de marzo). Uniatlántico: Fiscalía analiza posible peculado en puntajes de escalafón. https://bit.ly/35ObGyp

Ortiz Jiménez, J. y Vanegas Useche, I. (2001). Educación civíca en Colombia: una comparación internacional. Ministerio de Educación Nacional-Icfes.

Palacios, N. y Rodríguez, M. (2019). Los resultados de la prueba Saber 11 de Ciencias Sociales y las opiniones de los estudiantes: convergencias y divergencias. Revista Electrónica de Investigación Educativa, 21, 1-18. https://doi.org/10.24320/redie.2019.21.e28.2116

Perea Restrepo, C. (1996). Porque la sangre es espíritu: cultura política y violencia en Colombia. Instituto de Estudios Políticos y Relaciones Internacionales de la Universidad Nacional de Colombia.

Piaget, J. (1995). Essay on the theory of qualitative values in static ('Synchronic') Sociology. En L. Smith (ed.), Sociological Studies (pp. 97-133). Routledge.

Presidencia de la República de Colombia. (1950, 7 de junio). Decreto 2663 de 1950. Código sustantivo del trabajo. Diario Oficial n. ${ }^{\circ}$ 27.407. https://www.funcionpublica.gov.co/eva/gestornormativo/ norma.php?i=33104

Presidencia de la República de Colombia. (1994, 7 de enero). Ley 107 de 1994. Por la cual se reglamenta el artículo 41 de laConstitución Nacional y se dictan otras disposiciones. Diario Oficial n. ${ }^{\circ}$ 41.166. https://bit.ly/3lZueTE 
Presidencia de la República de Colombia. (1994, 8 de febrero). Ley 115 de 1994, "Por la cual se expide la Ley General de Educación". Diario Oficial n. ${ }^{\circ} 41.214$. https://www.funcionpublica.gov.co/eva/ gestornormativo/norma.php?i=292

Quaresma, M. y Villalobos, C. (2018). La reproducción de las élites en tiempos de democratización del sistema universitario. Análisis conceptual a partir de las experiencias latinoamericanas. Ciencias Sociales y Educación, 7(13), 65-87.https://doi.org/10.22395/csye.v7n13a3

Rawls, J. (1971). A theory of justice. Belknap Press.

Rawls, J. (1993). Political liberalism. Columbia University Press.

Rodríguez Rueda, Á. (1999). La Educación para la democracia en Colombia. En J. Torney-Purta, J. Schwille y J. Amadeo (eds), La educación cívica a través de los países: Veinticuatro estudios de casos nacionales del Proyecto Educación Cívica de la IEA (pp. 173-197). International Asociación Internacional para la Evaluación del Logro Educativo. https://bit.ly/3cUFcGm

Romero Espinosa, O. y Mejía Vélez, S. (2012). Nivel de conocimiento de la constitución Colombiana y actitud con respecto a participar en política en estudiantes próximos a graduarse como psicólogos en una universidad privada de Bogotá. Con-textos (9), 1-18. https://bit.ly/3zCjvoo

Romero Espinosa, O. y Mejía Vélez, S. (2013). Conocimiento de la constitución colombiana y de la actitud hacia la participación política en estudiantes de ingeniería. Cultura, Educación y Sociedad, 4(1), 21-39. https://bit.ly/3cPX4lG

Roth, A. y Robayo, F. (2015). Perfil y representatividad de la alta función pública del gobierno central de Colombia. Cuadernos de Administración, 31(54), 17-27. https://bit.ly/3wEGygh

Schulz, W., Ainley, J., Cox, C. y Friedman, T. (2018). Young people's views of government, peaceful coexistence, and diversity in five Latin American countries: IEA International Civic and Citizenship Education Study 2016 Latin American Report. Springer.

Shils, E. (1957). Primordial, personal, sacred and civil ties: some particular observations on the relationships of sociological research and theory. British Journal of Sociology, 8(2): 130-145. https:// doi.org/10.2307/587365

Semana. (2017, 3 de junio). Colombia vuelve a la mano dura. https://bit.ly/3wHYoz3

UK Parliament. (1998). European Parliamentary Elections Bill. https://bit.ly/3gDTj5n

Vallance, E. (1983). Hiding the Hidden Curriculum: an interpretation of the language of justification in nineteenth-century educational reform. En H. Giroux y D. Purpel (eds.), Hidden Curriculum and Moral Education: deception or discovery? (pp. 9-27). McCutchan Pub Corp.

Valencia Villa, H. (1987). Cartas de batalla: una crítica del constitucionalismo colombiano. Universidad Nacional de Colombia, Cerec.

Velandia, M. (2021, 8 de febrero). Muchas gracias, maestros, pero... 'next'. El Radical. https://elradical. info/muchas-gracias-maestros-pero-next/

Wasserman, M. (2021). La educación en Colombia. Debate. 